\title{
Finite-Difference Modeling of Two Aftershocks of the 1994 Northridge, California, Earthquake
}

\author{
by Craig W. Scrivner* and Donald V. Helmberger
}

\begin{abstract}
Recent evidence for nonlinear behavior of strong motions generated by the Northridge, California, earthquake relies explicitly on the analysis of aftershock data. Thus, correcting these observations for propagational and source effects becomes a crucial step in these studies. Here, we demonstrate that the dipping structure near the edges of the San Fernando Valley can strongly alter the local site responses, especially for shallow events.

We model two aftershocks with similar epicenters, but with shallow (4 km) and deep $(16 \mathrm{~km})$ hypocentral depths. Waveforms from 12 portable instruments deployed across the basin and recording these events were processed and studied in the 0.34-Hz bandpass. For the shallow event, distinctive features are a broad direct $S$ phase and large-amplitude surface waves at the basin stations, and high-frequency $S$ phases at stations in the Santa Monica Mountains. The deep event is less strongly affected by the basin but displays strong evidence of the source radiation pattern. An array analysis indicates 2D propagation for most of the strong arrivals. Some of these features are explained by a simple $2 \mathrm{D}$ basin model containing a strong shallow contrast, a factor of 2 jump in seismic velocity at a depth of $1 \mathrm{~km}$ within the basin, and a moderate deeper gradient.
\end{abstract}

Introduction

Over 7 weeks following the $M 6.717$ January 1994 Northridge, California, mainshock, a deployment of more than 100 portable stations recorded many aftershocks. This deployment generated a data set of high-quality, digital waveforms recorded in and around the San Fernando basin (Edelman and Vernon, 1994). These data provide an opportunity to do detailed analysis and modeling of the effects of the San Fernando basin on wave propagation. In this study, we examine how the interaction of seismic waves with the basin and the background structure differs for a shallow and deep source.

The San Fernando basin is a 4-5-km-deep sedimentary basin just north of Los Angeles (Fig. 1). The Northridge mainshock nucleated at a 16 to $19-\mathrm{km}$ depth under the southern edge of the basin, and it ruptured updip to the northeast to about a 5-km depth (Wald et al., 1996). The majority of aftershocks were in the shallow region of this fault plane and in a shallow cloud above the fault plane (Hauksson et al., 1995). Damage due to the mainshock was generally greatest in the northwest basin, though mitigated by the relatively sparse population in that area. Additional zones of heavy damage were just north of the Santa Monica Mountains in

*Present address: California Division of Mines and Geology, 801 K Street, MS 13-35, Sacramento, California 95814-3531.
Sherman Oaks and south of the mountains in Santa Monica and the northern Los Angeles basin. Significant directivity effects amplified ground shaking on the northern side of the basin (Dreger, 1994).

Wald et al. (1996) modeled the details of the source rupture process with a combined inversion of local strong ground motion, teleseismic, and geodetic data sets. For the local region, they used a $1 \mathrm{D}$ velocity model to generate synthetic Green's functions for the inversion. The source model they determined from the first 15-20 sec of local ground motions alone is consistent with models based on geodetic and teleseismic data sets and with the inversion of the combined data sets. Thus, the large-scale basin effects seem to be subdued compared to source effects.

Source studies of the Northridge aftershocks have been done with local and regional data by Hauksson et al. (1995) (first-motion data) and Thio and Kanamori (1996) (surfacewave data). Those two studies reached different conclusions for a significant number of events. Song and Helmberger (1997) inverted the broadband TERRAscope data, both $P_{n l}$ and surface-waves portions of the waveforms, to resolve these issues. Their results are more consistent with the depth and source parameters found by Hauksson et al. (1995) and are used in this study.

Most of the aftershocks are farther north than the main- 


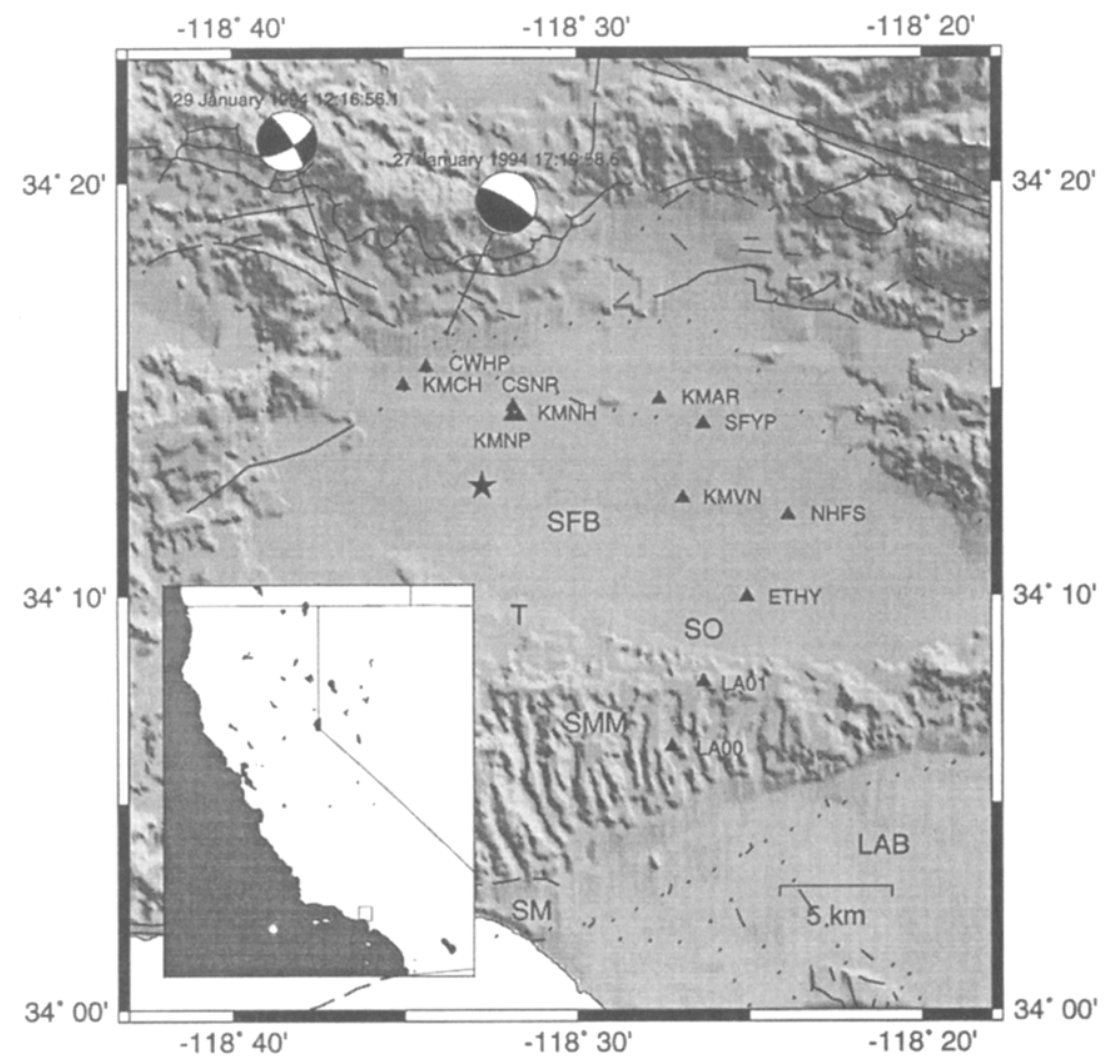

Figure 1. Map of San Fernando basin and surrounding topography. Focal mechanisms of the aftershocks analyzed in this study are shown in lower-hemisphere projection. Triangles are seismic receivers used in this study. The thin black lines depict a few of the significant faults in the area. The star indicates the epicenter of the mainshock. The small square on the map of California indicates the location of the study region. In addition to the station codes, the following locations are labeled: SFB, San Fernando basin; LAB, Los Angeles basin; T, Tarzana; SO, Sherman Oaks; SMM, Santa Monica Mountains; SM, Santa Monica. shock, in locations that are more likely to produce basinedge effects. Pitarka and Irikura (1996) and Haase et al. (1996) calculated synthetic waveforms for 2D models to compare with waveform data from an aftershock at the north side of the basin, near the epicenter of the 1971 Sylmar earthquake. Pitarka and Irikura's model combines a model of the San Fernando and Los Angeles basins similar to that in Vidale and Helmberger (1988) with a cross section from the $3 \mathrm{D}$ tomographic model of the area by Zhao and Kanamori (1995). With this structure, they can explain some secondary arrivals at sites in the San Fernando basin and the Los Angeles basin.

More recent reports have concentrated on the differences in response between aftershocks and mainshock as recorded at the same sites. Strong site effects are eliminated by working with ratios, and these results demonstrate a depletion of high-frequency energy for the mainshock indicative of nonlinear effects (Field et al., 1997, 1998; Beresnev and Atkinson, 1998; Beresnev et al., 1998a, b; Cultrera et al., 1998; Su et al., 1998). While such results seem compelling, there are some other possible explanations that could help explain the extreme variability. In particular, the radiation pattern differences are neglected, and path effects are corrected by a simple $1 / R$ amplitude decay relation or $1 \mathrm{D}$ models. Both features are poorly understood in the primary frequency range of interest, $1-10 \mathrm{~Hz}$, and it is difficult to perform meaningful improvements.

In this report, we attempt to assess these features by concentrating on two aftershocks with similar epicenters, but with hypocentral depths of 3.6 and $16 \mathrm{~km}$ (Table 1). The two events are located in the northwest corner of the San Fernando basin (Fig. 1) and have distinctly different source mechanisms, as displayed. They were both recorded by the same set of stations so that differences in radiation pattern and path effects can be studied directly and modeled to some extent.

\section{Data}

The waveforms analyzed and modeled in this study were recorded during the deployment of portable instruments following the Northridge mainshock. The deployment involved a number of institutions associated with the Southern California Earthquake Center (SCEC) (Edelman and Vernon, 1994). It included both broadband and shortperiod velocity sensors, and strong-motion accelerometers. GPS or Omega clocks were used to maintain timing accuracy at most sites, though a few stations had large timing errors, and some deployed instruments had only internal clocks, subject to drift. Over the period it was deployed, the portable network recorded 46 events with magnitudes over 4.0 .

The waveforms were integrated to displacement and bandpass filtered with corners at 0.3 and $4 \mathrm{~Hz}$. The relatively short long-period corner of the filter was required for stable integration. The high-frequency corner of the filter is dic- 
Table 1

Events Analyzed and Modeled in this Study. The Source Parameters of Strike, Rake, Dip, and Moment are from Song and Helmberger (1997). The Depth is from Hauksson et al. (1995).

\begin{tabular}{cccccrr}
\hline Date & Time & Strike & Rake & Dip & Moment & Depth \\
\hline January 29, 1994 & $12: 16: 56.08$ & 60 & 10 & 70 & $2.3 \times 10^{22}$ & 3.6 \\
January 27, 1994 & $17: 19: 58.58$ & 120 & 90 & 10 & $4.3 \times 10^{22}$ & 16.3 \\
\hline
\end{tabular}

tated by the onset of grid dispersion in the finite-difference synthetic waveforms that data will be compared against later.

Timing of some records was adjusted to account for known timing errors and uncertainties at some stations (Edelman and Vernon, 1994). The timing shifts are listed in Table 2. Station CWHP has a timing error of approximately $2 \mathrm{sec}$ identified by Edelman and Vernon. KMCH, KMNP, KMNH, KMAR, and KMVN ran on internal clocks and were subject to drift. We applied ad hoc timing adjustments to these records based on the timing of nearby stations with accurate timing.

Waveforms from the shallow event (Fig. 2a) show indications of strong interaction with the basin. The stations can be grouped by distance into four clusters at $<5 \mathrm{~km}, 8$ $\mathrm{km}, 14-17 \mathrm{~km}$, and $20-25 \mathrm{~km}$. The direct shear wave on the tangential component is the dominant phase in the first cluster, stations $\mathrm{KMCH}$ and CWHP, with possibly a shallow basin multiple $3 \mathrm{sec}$ behind the direct arrival. The second cluster, stations CSNR, KMNP, and KMNH, display the most obvious basin effects in the record section. On the tangential component, there are two or three cycles of basin-generated surface waves that can be correlated across the three traces. The third cluster, stations KMAR, SFYP, and KMVN, is spread across the north-central portion of the basin. The waveforms have relatively little coherence among them. KMVN records a late, large-amplitude pocket of energy starting 3-4 sec after the direct shear wave. The fourth cluster, stations NHFS, ETHY, LA01, and LA00, extends from the center of the basin south across the Santa Monica Mountains. The transition out of the basin, at station LA01, has surprisingly high amplitude and ringing phases after the direct shear wave on the horizontal components.

Compared to the shallow event, waveforms recorded from the deep event (Fig. 2b) show relatively little effect from the basin. The deep event is approximately $5 \mathrm{~km}$ east of the shallow event, so the stations are about $3 \mathrm{~km}$ closer to the deep source than they are to the shallow source. In discussing the deep event data, however, the same clustering of stations as before can be used. At all stations, the direct shear wave is the strongest arrival. The second cluster of stations has a prolonged coda, but only a single discrete arrival $4 \mathrm{sec}$ after the direct $S$ that might be a basin-edgeinduced multiple. The third station cluster has variable waveform amplitude, as in the case of the shallow source, and station KMVN again has a large-amplitude coda that starts $4 \mathrm{sec}$ after the direct $S$. In the fourth station cluster,
Table 2

Time Shifts Applied to Data from the Two Northridge Aftershocks

\begin{tabular}{ccc}
\hline Event & Station & Shift (sec) \\
\hline January 29, 1994, & CWHP & -2.0 \\
$12: 16: 56.08$ & KMCH & 0.9 \\
& KMNP & 1.2 \\
& KMNH & 0.8 \\
& KMAR & 1.0 \\
& KMVN & 1.2 \\
January 27, 1994, & KMNP & -0.8 \\
$17: 19: 58.58$ & KMNH & -0.6 \\
\hline
\end{tabular}

station LA01 again has large-amplitude ringing immediately after the direct $S$.

Despite the waveform comparison that suggests waves from the deep source do not interact strongly with the basin, the pattern of peak amplitudes is quite similar for the two events. In the second cluster, CSNR has the largest horizontal amplitudes for both events, and KMNP and KMNH share very similar amplitudes. In the third cluster, SFYP has the smallest and KMVN has the largest amplitudes. In the fourth cluster, LA01 has the largest amplitudes on all three components. As noted earlier, the waveforms from stations KMVN and LA01 also indicate some extreme local site complexity.

The cluster of stations CSNR, KMNP, and KMNH is tightly enough spaced that an array analysis based on the coherence of the wave shape can be applied. We used the technique employed by Frankel et al. (1991) in the Santa Clara Valley on data from a dense array that recorded aftershocks of the 1989 Loma Prieta earthquake. This involves cross-correlating the waveforms in order to find the backazimuth and apparent velocity of a plane wave that best fits the timing of phases in the waveforms. Unfortunately, stations KMNP and KMNH ran on internal station clocks and the raw timing is inaccurate. We assume that the direct $S$ wave arrives on azimuth from the source with an apparent velocity of $3 \mathrm{~km} / \mathrm{sec}$ for the shallow event and $4 \mathrm{~km} / \mathrm{sec}$ for the deep event, and set the timing of KMNP and KMNH relative to CSNR. An analysis of surface waves with low apparent velocities is insensitive to the exact values assumed for the direct arrival (S. E. Hough, personal comm.). The analysis is applied repeatedly on a narrow, sliding time window. We use a 1.25-sec window, which is similar to the dominant period of the basin-generated waves. The analysis is applied 


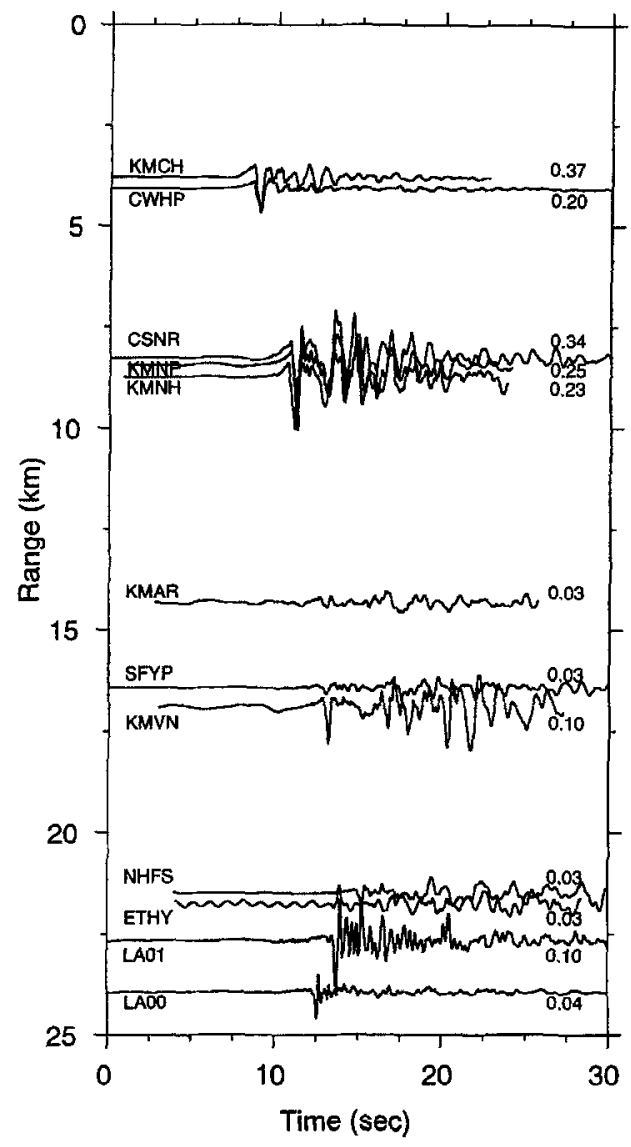

(a) Shallow - Event 12:16

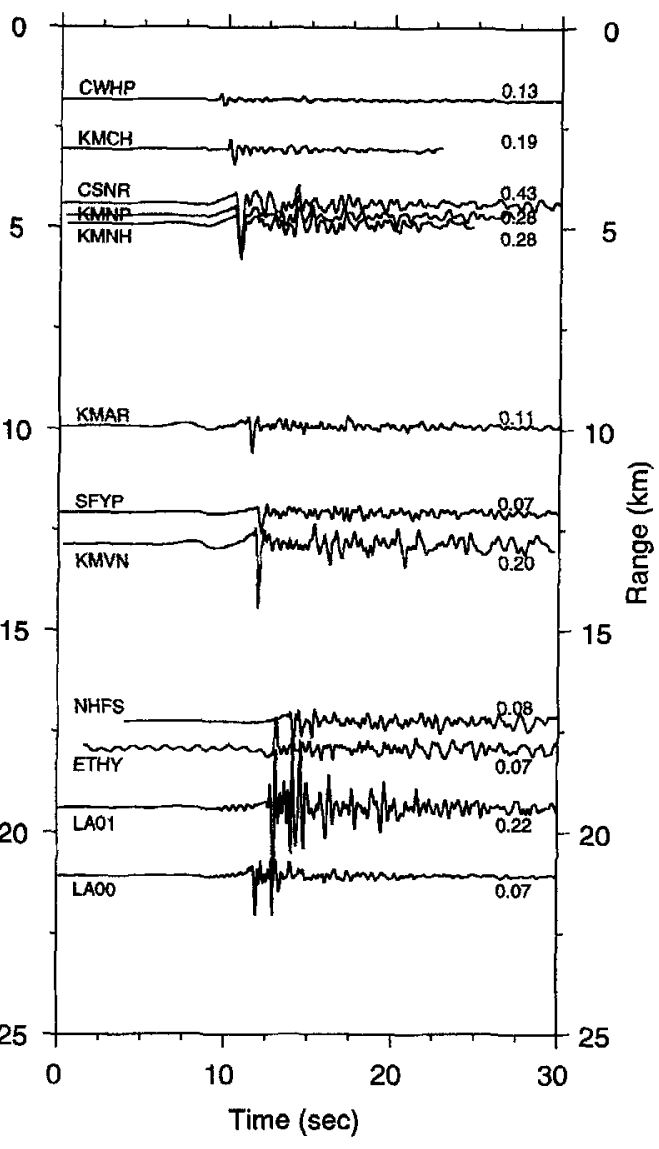

(b) Deep - Event 17:19

Figure 2. Record sections of tangential-component displacement waveforms for the two aftershocks used in this study. Station names are on the left of each trace. Peak amplitudes (in $\mathrm{cm}$ ) are on the right. Records are shown in absolute time, where available, with the origin at $5 \mathrm{sec}$. Stations with unknown timing are shifted as needed relative to a station with known timing. Waveforms are plotted in absolute amplitude scaled by range from the source.

every $0.5 \mathrm{sec}$ along the waveforms. Only points for which the correlation is greater than $80 \%$ are shown.

The array analysis for tangential component records of the shallow event is shown in Figure 3. Apparent velocity $\left(V_{\text {app }}\right)$, initially constrained to a value of $3 \mathrm{~km} / \mathrm{sec}$, fluctuates and gradually decays to below $1 \mathrm{~km} / \mathrm{sec}$. In the first $4 \mathrm{sec}$ after the direct $S$ phase, spanning the largest amplitude basin reverberations, the backazimuth of arriving energy fluctuates slightly but stays between the station-epicenter backazimuth and north (a $60^{\circ}$ range). Further into the records, the backazimuth shifts rapidly between arriving on azimuth, arriving from the south, and arriving from the northeast. The number of windows in which the correlation is high falls toward the end of the records where the waveform amplitudes are low and coda has developed.

The array analysis for tangential records of the deep event is shown in Figure 4. Compared to the shallow event analysis, there are fewer time windows with waveform correlations greater than $80 \%$. This indicates that the basin is producing fewer coherent phases with high energy. Wave fronts from a deep source should be subhorizontal with high $V_{\text {app }}$. Therefore, it is interesting to note that where the backazimuth is nearly on azimuth, $V_{\text {app }}$ tends to be higher. Offazimuth arrivals are similar to those seen for the shallow event, from the south and from the northeast. Energy arrives from the south with low $V_{\text {app }}$ immediately after the direct $S$ wave. This suggests a weak scatterer just south of the station cluster, rather than energy propagating all the way from the south edge of the basin. Energy from the northeast arrives later in the record and could be explained by the main structure of the basin further from the stations.

\section{Modeling}

We used a forward modeling, trial-and-error approach to model the waveforms. Synthetic waveforms were calculated for each working model by a two-dimensional finitedifference numerical technique (Vidale et al., 1985; Helm- 
12:16 (CSNR, KMNP, KMNH Cluster)
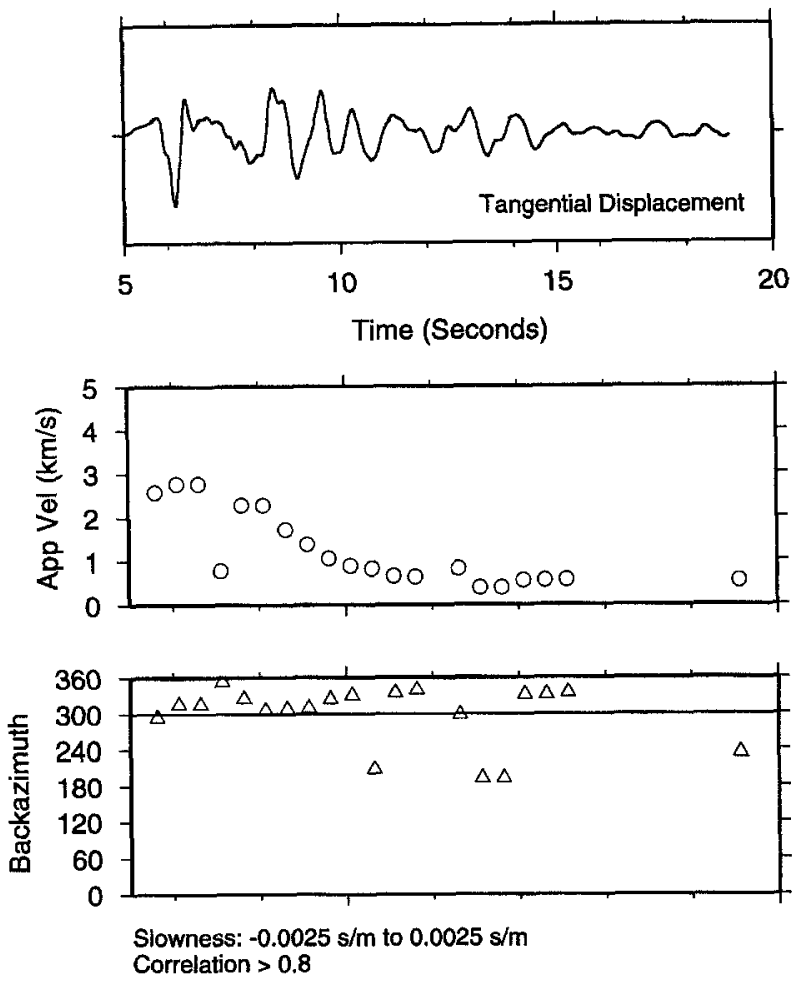

Figure 3. Array analysis for the shallow event of the tangential component at station cluster CSNR, KMNP, and KMNH. Apparent velocity and backazimuth are determined. The trace from CSNR is shown for reference. The line at $300^{\circ}$ indicates the true backazimuth of the stations to the source. Only points from time windows with station cross-correlation greater than 0.8 are shown.

berger and Vidale, 1988). The algorithm is a centered-grid scheme, fourth order in space and second order in time, with absorbing boundary conditions (Clayton and Engquist, 1980). Attenuation is not incorporated in the code. The response for an arbitrary double-couple source can be calculated. For the two events, the source parameters of Song and Helmberger (1997) were used (Table 1), which are similar to those found by Hauksson et al. (1995). The 0.3- and 0.2sec triangle source time functions were convolved into the waveforms for the shallow event and the deep event, respectively.

After each calculation, we compared the synthetic waveforms with the data waveforms and made adjustments to the model. The distinctive features in the data discussed earlier were the focus of the modeling. Some features suggested a starting point for the modeling. The surface waves $2 \mathrm{sec}$ after the direct $S$ at CSNR, KMNP, and KMNH (and the lack of such phases at KMCH and CWHP) suggest the basin edge starts a few kilometers from the source. The surface waves have 1-sec period, and this implies a strong gradient within the basin. The Hilbert transformed direct $S$ phases at
17:19 (CSNR, KMNP, KMNH Cluster)
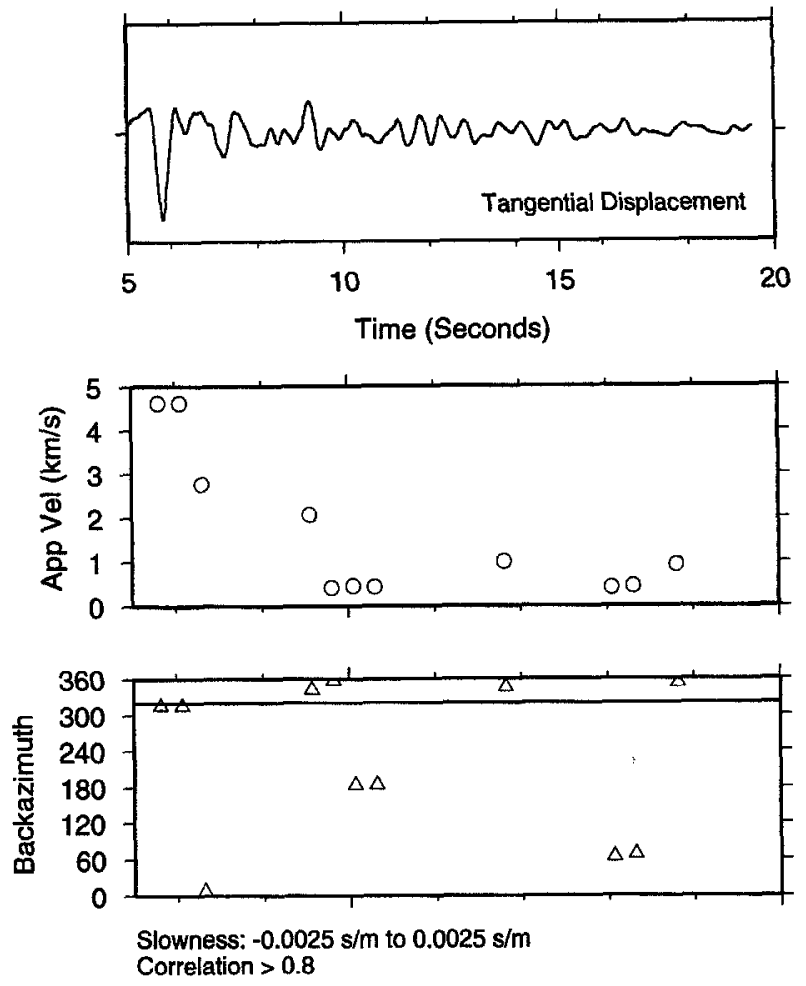

Figure 4. Same as Figure 3, but for the deep event. The true backazimuth of the cluster is $320^{\circ}$.

LA01 and LA00 suggest a gradient beneath the basin to generate a triplication effect. The abrupt termination of basin phases from ETHY to LA00 in conjunction with the onset of the Hilbert transformed direct $S$ at LA01 and LA00 place some constraints on the southern edge of the basin.

Our preferred model for this cross section through the San Fernando basin is shown in Figure 5. The basin is defined by two zones of high-velocity contrast. The shallow event is just below the bottom of the basin. The high-contrast interface at about $1 \mathrm{~km}$ is a midbasin gradient that controls critical reflection basin-edge trapping. The bottom of the basin at $3.5 \mathrm{~km}$ turns a greater percentage of energy radiated from the source up into the basin-edge structure. This shallow basin-edge structure controls the timing and period of the surface waves. The interfaces 2 to $3 \mathrm{~km}$ below the source critically reflect energy 20 to $25 \mathrm{~km}$ from the source and form a triplication phase. Turning this energy up sharply around the southern edge of the basin requires a gradient 1 to $3 \mathrm{~km}$ beneath the surface of the Santa Monica Mountains. A shallow dip on this edge of the basin tends to direct basintrapped energy under the Santa Monica Mountains rather than along the surface (i.e., the tunneling effect reported by Vidale and Helmberger [1988]).

Figure 6 shows record sections of observed and synthetic waveforms for the shallow event. The variation in waveform as a function of distance is fit fairly well. There 


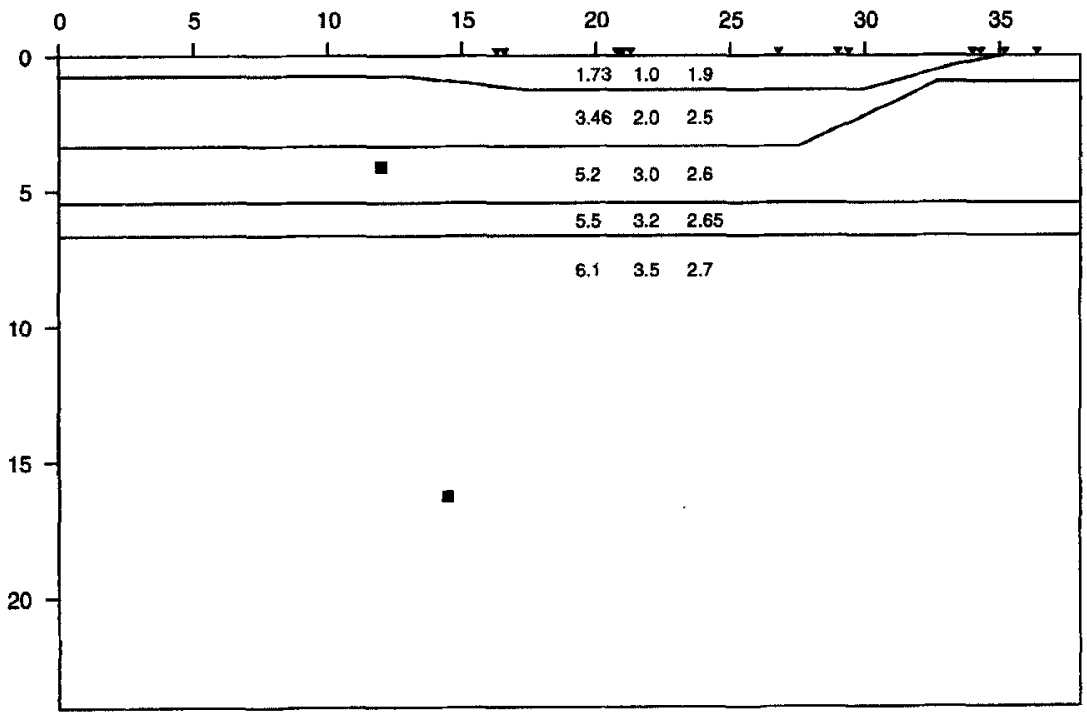

Figure 5. Two-dimensional model of the Northridge basin used to generate synthetic waveforms. Range and depth in kilometers. Squares indicate the two source locations used in the calculations. Triangles are receiver locations for the stations in this study. For each layer, the compressional velocity, shear velocity, and density are listed from left to right. The velocities have units of $\mathrm{km} / \mathrm{sec}$, and density has units of $\mathrm{g} / \mathrm{cm}^{3}$. are multiple cycles in the surface-wave group following the direct shear wave at stations CSNR, KMNP, and KMNH. The relative amplitude of the surface waves to the direct arrival is correct on the tangential component, though not on the radial and vertical components. Also, the ratio of peak amplitudes of the tangential to radial component is good. At stations KMAR, SFYP, and KMVN, the most notable feature is the amplitude of KMVN relative to the other two stations. On the tangential component, this amplitude and waveform variation is fit quite well. However, on the radial and vertical synthetics, there is little variation between the stations. Finally, the variation in the direct shear wave between stations NHFS, ETHY, LA00, and LA01 is fit by the triplication structure below the source. The flip in polarity on the tangential component at ETHY is not fit. The extreme variation in ringing phases from NHFS to LA01, in shape, period, and amplitude is not fit by this model. We discuss this at more length in a later section.

Across the three components, the amplitudes of the data at the first pair of stations are poorly fit by the synthetic waveforms. However, the error is not systematic in a way that suggests a change in the model. The large variation between components at $\mathrm{KMCH}$ can be explained by a source $S V$ minima and $S H$ maxima on this azimuth. Synthetics for the second cluster of stations are about half that of the data on the radial and tangential components but a little high on the vertical component. As previously mentioned, at the third cluster of stations, the variations among the stations are fit well in waveform and amplitude on the tangential component but not on the other components. The tangential component synthetics for KMAR and SFYP are affected by an $S H$ node along the azimuth to those stations. If a different source mechanism is applied to the synthetics, for example, the mechanism of the deep event, then amplitudes are similar to those at station KMVN (Fig. 7).

In the data, the ringing on KMVN must be explained by some other phenomenon that effects both $S H$ and $P-S V$ waves. For the last cluster of stations, the high amplitudes in the data on the radial and tangential components of LA01 are not generated by the model. Instead, stations LA00 and LA01 have similar amplitudes. The low velocities on the radial and vertical components of the synthetics of these two stations are due to the $S V$ node at this azimuth. The data seem less sensitive to this node. Overall, the synthetic waveform amplitudes are much more sensitive than the data to nodes in the source radiation pattern and indicate that at stations KMVN and LA01, some additional phenomenon (small-scale 3D) is probably occurring to increase data amplitudes and complexity.

Figure 8 shows record sections of the observed and synthetic waveforms for the deep event. The synthetics for the deep event are characterized by simple waveforms dominated by the direct shear wave. Moderately sized multiples (less than $50 \%$ of the amplitude of the direct arrival) are generated at sites in the basin. On the tangential component, the largest amplitudes are seen at the second cluster of sites (CSNR, KMNP, and KMNH). On the radial component, the largest amplitudes are at the first two stations. The vertical waveforms are relatively subdued (note that this component is plotted at twice the amplitude to improve viewing); neither the direct $P$ nor the direct $S$ phase stands out consistently from the coda. These features in the synthetic waveforms are a good match to the data.

In the data, the polarities of the third station cluster on the radial component are problematic. SFYP appears to be flipped, but the synthetics are consistent with the SFYP polarity. This suggests a combination of polarity problems in the data and an inaccurate source mechanism used in the synthetics with the node crossing occurring between KMNH and KMNR. The shallow event does not clarify the problems with these stations because of the long-period noise at KMAR and KMVN and the emergent direct $S$ arrival at SFYP. In the 
Event: 12:16 [Displacement, Bandpass 0.3 to $4 \mathrm{~Hz}$ ]

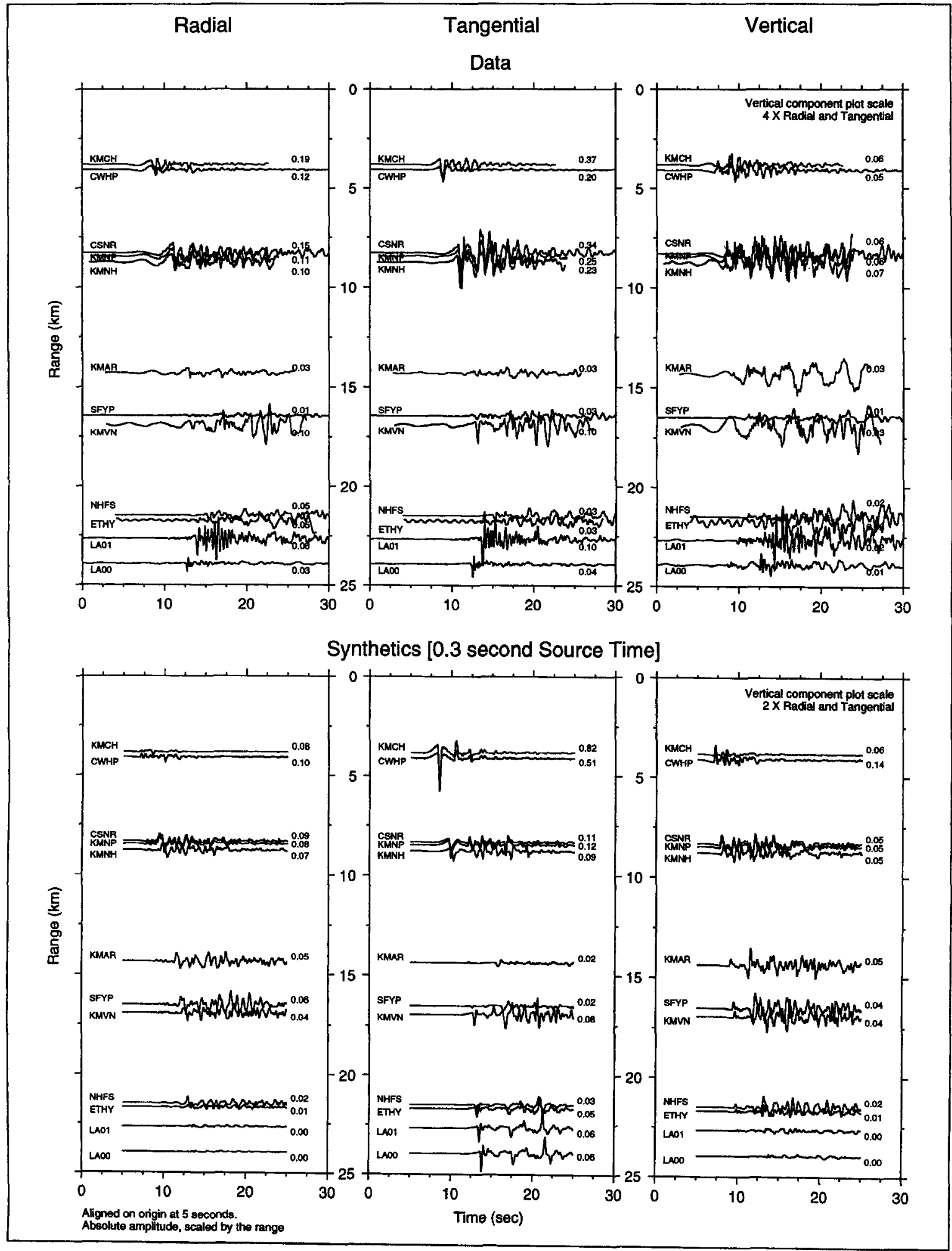

Figure 6. Observation and synthetic record sections of displacement waveforms for the shallow event, 29 January 1994, 12:16:56.1. Station names are on the left of each trace. Peak amplitudes (in $\mathrm{cm}$ ) are on the right. Records are shown in absolute time, where available, with the origin at 5 sec. Stations with unknown timing are shifted as needed relative to a station with good timing. Waveforms are plotted in absolute amplitude scaled by range from the source. Note that the vertical-component data are plotted with a factor of 4 magnification, and the vertical-component synthetics are plotted with a factor of 2 magnification. This is done to improve the visibility of the vertical waveforms. 


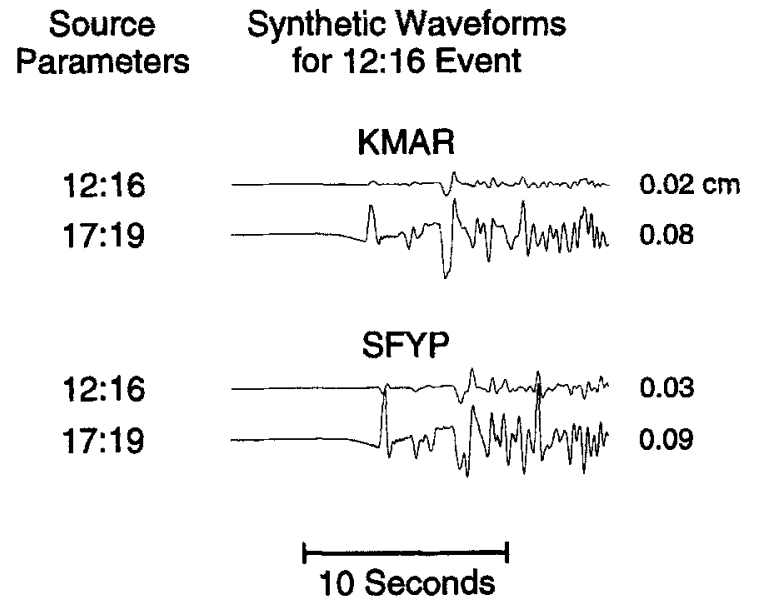

Figure 7. Example of variations in synthetic waveforms with changes in source mechanism parameters. The source location, depth, and moment of event 12:16 are used for all synthetics. The label on the left indicates whether the strike, rake, and dip of $12: 16$ or $17: 19$ was used.

fourth station cluster, on the tangential component, the polarity of direct $S$ seems to be flipped at ETHY, but this could be caused by a local site response. This behavior is also seen for the shallow event (Fig. 6).

In the data for both the shallow and deep events, the amplitudes and waveforms at stations LA01 and KMVN appear anomalous. As mentioned earlier, the contrast of SFYP and KMVN on the tangential component of the shallow event could be explained as a source effect. However, the source mechanism does not explain the radial component at these stations or either of the components at station LA01. For the deep event, the source mechanism does not explain the large coda and high peak amplitudes at either LA01 or KMVN. The most likely explanation is shallow site response. LA01 is in Sherman Oaks, an area which suffered significant damage in the Northridge mainshock. Hartzell et al. (1996), in a study of site response in the San Fernando and northern Los Angeles basins, found strong but variable site effects in Sherman Oaks. They suggest both the amplitude and variation of the effect could be explained by Quaternary deposits of the Los Angeles River. Station KMVN sits in the center of the San Fernando basin on a broad, coarse alluvial surface (Tinsley and Fumal, 1985). The surface geology does not immediately differentiate this site from those of surrounding stations. Unlike at LA01, the large coda at KMVN does not start immediately after the direct $S$ arrival. Also, the ringing is at a lower frequency than at LA01. These factors suggest that the site response at KMVN is due to a somewhat deeper and broader structure.

\section{Model Sensitivity}

In contrast to full 3D finite-difference calculations, 2D finite-difference calculations can be done much more rap- idly. We take advantage of this feature of $2 \mathrm{D}$ modeling to explore the model parameter space. Here we compare synthetic waveforms for models perturbed away from our preferred model (Fig. 9). We show data and synthetics for the station most strongly affected by that portion of the model. In each case, the waveforms are lined up on the direct shear wave of the data and normalized to the same amplitude to aid in comparison of wave shape. Only the tangential component and waveforms from the shallow event are shown.

The upper basin controls the surface waves $2 \mathrm{sec}$ after the direct shear wave at stations CSNR, KMNP, and KMNH. The effect of changes to the velocity contrast at this interface, the point of onset of the basin edge, and the depth to the bottom of the upper basin are shown in Figure 10. The propagation is least strongly effected by changes to the point of onset of the basin edge (Fig. 10b). Altering the velocity contrast across the basin and changing the depth of the basin produce similar, strong effects. The preferred model has a basin that starts at $0.5 \mathrm{~km}$ depth and goes down to $1-\mathrm{km}$ depth (Fig. 10c). Hence, dropping the bottom by $0.4 \mathrm{~km}$ adds almost $50 \%$ to the basin depth, and raising the bottom by the same amount almost completely removes the basin. With a deeper basin, the energy is trapped into a nearly harmonic packet. In comparison to the data, the surface-wave packet in this synthetic is a bit short in duration and high in frequency. This waveform is remarkably similar to the synthetic from the model with the original basin depth but with $15 \%$ greater velocity contrast across the interface (Fig. 10a). Clearly, trade-offs can be found between basin parameters. The synthetics from the very shallow basin and the reduced contrast models indicate conditions in which basin phases are not trapped. The contrast of $1.3 \mathrm{~km} / \mathrm{sec}$ over $2.0 \mathrm{~km} / \mathrm{sec}$ is still fairly high, but the shallow basin structure is not tuned for critical angle reflections and basin resonance with these velocity parameters.

The second interface in the model is effectively the bottom of the lower basin. We examine the impact of variations in this structure at a station in and just beyond the basin in Figure 11. In our final model, the basin is flat on the leading edge and ramped up at the trailing edge. Figure 11a indicates the insensitivity of source-receiver geometry of this data set to the dip on the leading edge of the deep basin. The model is quite sensitive, however, to the depth of the basin relative to the source (Fig. 11b). This interface turns energy up from the source into the leading edge of the upper basin. When the basin bottom is moved up away from the source, the amount of energy in the upper basin surface waves is reduced. Also, the duration over which energy enters the upper basin is changed.

The direct shear wave that arrives at the trailing edge of the basin leaves the source as down-going energy and turns without significant distortion by the basin. The direct $S$ arrival in the records at LA01 and LA00 is phase shifted relative to stations in the basin. In our model, we explain this phase shift as a triplication formed by a gradient below the source. This phase is sensitive to the structure just be- 
Event: 17:19 [Displacement, Bandpass 0.3 to $4 \mathrm{~Hz}$ ]

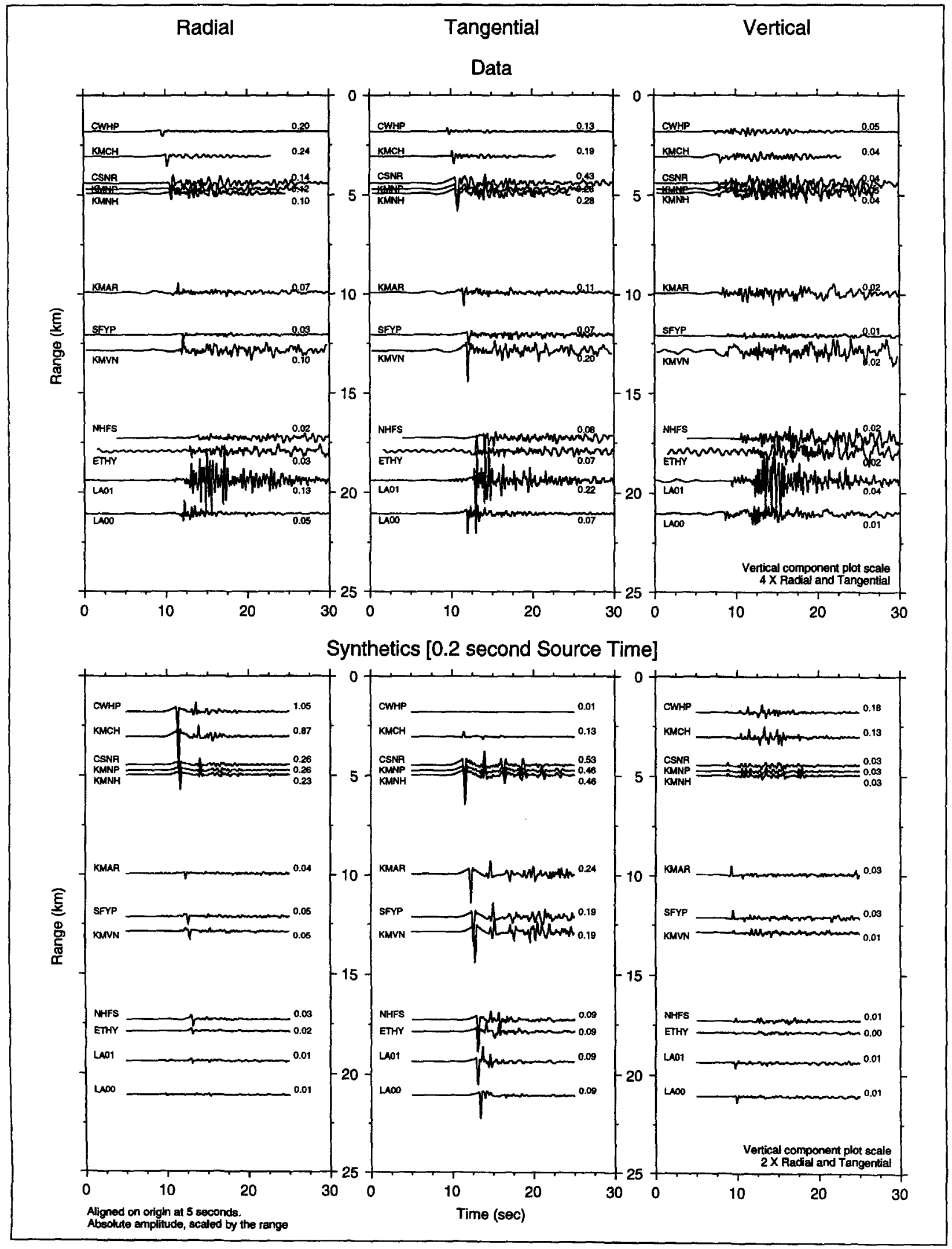

Figure 8. Observation and synthetic record sections of displacement waveforms for the deep event, 27 January 1994, 17:19:58.6. Plotting conventions are the same as those in Figure 6. 


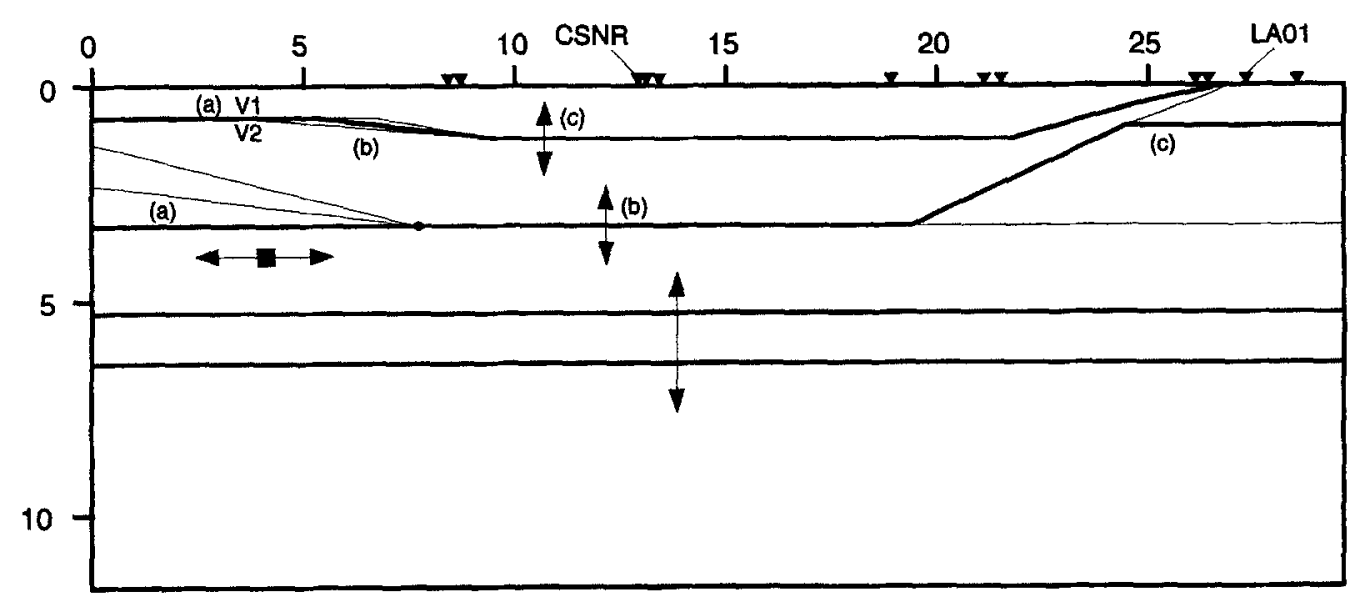

Figure 9. Variants of the Northridge basin velocity model for which synthetic waveforms are shown in Figures 10-12. Different cases marked by lowercase letters correspond to subfigures in those figures. Thin lines and arrows indicate how the model is perturbed in each case. Calculations were done for the shallow source location (black square).

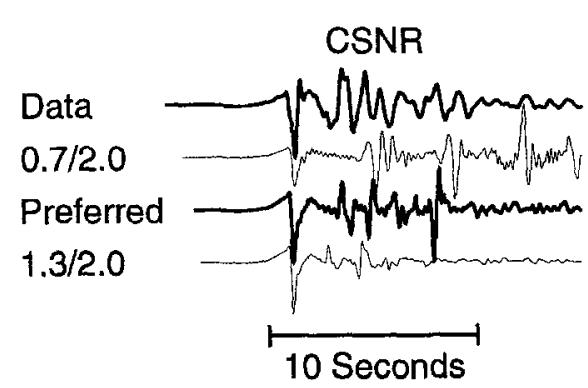

(a) Velocity contrast

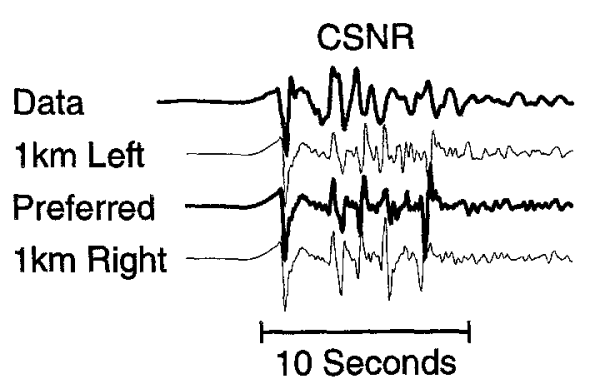

(b) Edge onset and steepness

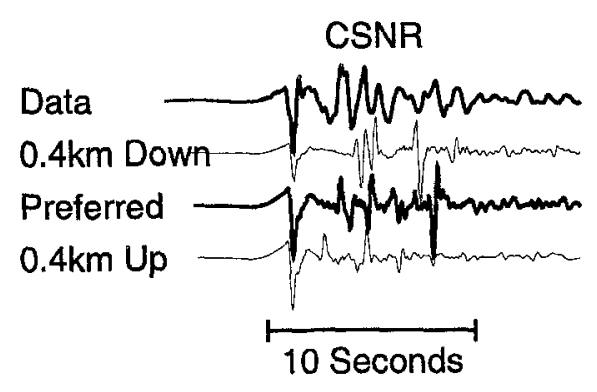

(c) Depth to bottom

Figure 10. Effect on the waveform at CSNR from changes to the structure of the upper basin. Data and synthetic waveforms for the preferred model plotted with heavier lines. All traces are aligned with direct shear wave of the data and plotted at the same height.

yond the upper basin because arrivals from two interfaces have to arrive in sync (Fig. 11c). In particular, the preferred and the flat interface models for the trailing basin edge introduce a phase shift to the first arrival, while the model in which the trailing edge reaches the surface does not. This indicates that a velocity gradient is needed in the Santa Mon- ica Mountains at a few kilometers depth to turn seismic waves around the basin.

Figure 12 suggests the sensitivity of this phase to the depth of the interface that produces it. This phase should also be sensitive to the velocities across the interface. It depends on seismic waves turning at critical angle and reaching 


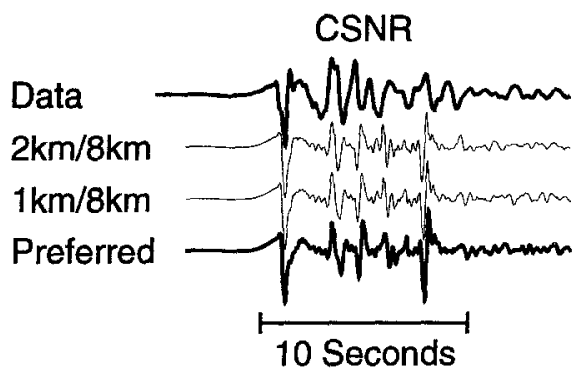

(a) Edge steepness

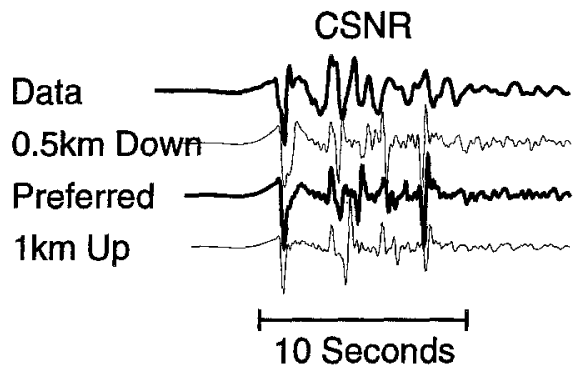

(b) Depth to bottom

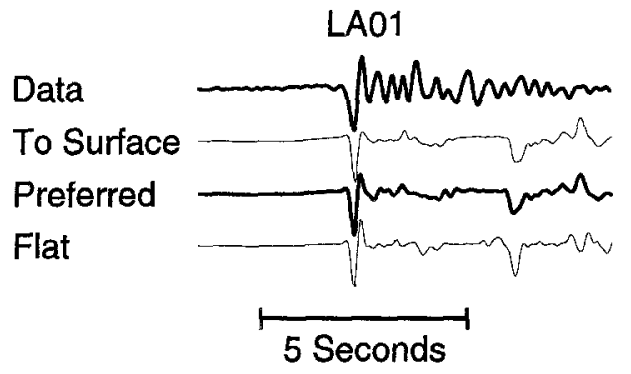

(c) Dip of trailing edge

Figure 11. Effect on the waveform at CSNR from changes to the structure of the leading edge and center of the lower basin, and the effect on the waveform at LA01 from changes to the trailing edge of the lower basin.

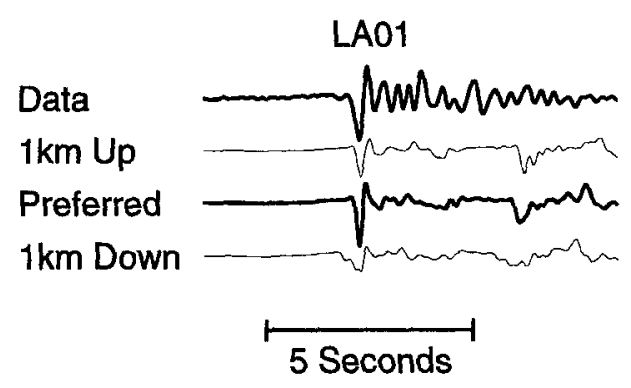

Figure 12. Effect on the waveform at LA01 from changes to the depth of the interfaces below the source.

sites just beyond the basin. The sites involved are just 20 $25 \mathrm{~km}$ from the source, so this geometry is fairly tightly constrained.

\section{Discussion}

The cross section we have modeled runs from the northwest corner of the San Fernando Valley to the southeast and into the central Santa Monica Mountains. Vidale and Helmberger (1988) modeled data from the 1971 Sylmar earthquake over a cross section from the northeast corner of the basin, in the 1971 epicentral region, south and west into the Los Angeles basin. Haase et al. (1996) and Pitarka and Irikura (1996) modeled a Northridge aftershock along a similar cross section. These lines pass over a deeper portion of the San Fernando basin, in the northeast, than we sample with our data set. Nonetheless, it is useful to compare our model with these earlier results.

Vidale and Helmberger (1988) based their model on borehole data that constrains the depth and seismic velocities of portions of the basin (Duke et al., 1971). The model has a fairly constant gradient throughout the basin from $V_{\mathrm{s}}=$ $0.6 \mathrm{~km} / \mathrm{sec}$ in the top $0.5 \mathrm{~km}$ to $1.8 \mathrm{~km} / \mathrm{sec}$ at $4 \mathrm{~km}$. There is a stronger gradient at the bottom of the basin from 1.8 to $3.5 \mathrm{~km} / \mathrm{sec}$ over less than a kilometer. The background model is from Kanamori and Hadley (1975), with $V_{s}=4.0$ $\mathrm{km} / \mathrm{sec}$ at about $8 \mathrm{~km}$. We have a similar depth of basin, but with lower contrast across it $\left(V_{\mathrm{s}}=2\right.$ to $\left.3 \mathrm{~km} / \mathrm{sec}\right)$. In the midbasin, we have a stronger contrast at $1 \mathrm{~km}$ depth. Below the basin, our model is $0.5 \mathrm{~km} / \mathrm{sec}$ slower from 4 to $6 \mathrm{~km}$. Our model does not include a region with $4 \mathrm{~km} / \mathrm{sec}$ at greater depth as suggested by Kanamori and Hadley (1975).

Haase et al. (1996) took their cross section from a 3D tomographic model of the southern California crust. It was an earlier version of the more recently published 3D model of Hauksson and Haase (1997). The velocities in the top 0.5 $\mathrm{km}$ of the original tomographic model were reduced by $50 \%$ to account for the insensitivity of the tomographic model to shallow velocities. In the San Fernando basin, this results in a minimum shear velocity of about $1 \mathrm{~km} / \mathrm{sec}$. The strongest gradient in the model is at about $3 \mathrm{~km}$ depth with the velocity rising from 2.5 to $3.3 \mathrm{~km} / \mathrm{sec}$. Haase et al. (1996) comment 
that this gradient may be a residual effect of the starting model in the tomographic inversion, but it is consistent with the depth of basin in our model. This gradient extends across the entire tomographic section, including into the Los Angeles basin. A velocity of about $3.5 \mathrm{~km} / \mathrm{sec}$ extends down as far as $8 \mathrm{~km}$ in the San Fernando basin in the tomographic model, which seems inconsistent with the structure we need to generate the phase-shifted direct $S$ arrival beyond the basin. In the most recent tomographic model of Hauksson and Haase (1997), the depth profile in the east Ventura basin has a strong gradient in $P$ velocity from 4 to $6 \mathrm{~km}$ depth. This is more consistent with the depth of the gradient below the basin in our model.

Pitarka and Irikura (1996) patched together a shallow basin structure based on that in Vidale and Helmberger (1988) and a cross section from the 3D tomography of the San Fernando basin from Zhao and Kanamori (1995) for the deeper crustal structure. We have already commented on the basin component of this model. Excluding the top $5 \mathrm{~km}$ of the cross section from Zhao and Kanamori, which are replaced by the Vidale and Helmberger (1988) structure, the model has $V_{\mathrm{p}}=5.6$ to $6.2 \mathrm{~km} / \mathrm{sec}$ and $V_{\mathrm{s}}=3.2$ to $3.6 \mathrm{~km} /$ sec down to about $20 \mathrm{~km}$ under the San Fernando Valley. This is significantly slower than the background 1D model of Vidale and Helmberger. It is similar to velocities in our model, but lacks the gradient around 5 to $6 \mathrm{~km}$ in our model that generates the triplication phase beyond the basin.

In addition to the models used in these 2D studies, 3D calculations for the response of the Los Angeles and San Fernando basins have been done by Olsen et al. (1995) and Olsen and Archuleta (1996) with a 3D model by Magistrale et al. (1996). Magistrate et al. constructed a geology-based 3D velocity model of the Los Angeles area. Their model for the San Fernando basin has since been refined (Magistrale, personal comm., 1997). The new model has a strong upper basin gradient from $V_{\mathrm{s}}=1$ to $2 \mathrm{~km} / \mathrm{sec}$ at about $1 \mathrm{~km}$ depth, but the deep basin in this model is 1 to $2 \mathrm{~km}$ shallower than ours. Outside the basin, shear velocities are about $3 \mathrm{~km} / \mathrm{sec}$ with a slight vertical gradient. The velocity jumps to $3.5 \mathrm{~km} /$ $\mathrm{sec}$ at $5.5 \mathrm{~km}$. This is based on the Hadley and Kanamori (1977) model for the crust in the Transverse Ranges. The depth and velocity contrast of this interface is similar to the gradient producing the triplication in our model.

The variation in background seismic velocity structure in the three models previously described is fairly large. The waveform modeling in this study indicates that data sets from shallow earthquakes at local distances may have features that can constrain this structure. Of the models discussed here, our model is most consistent with the background structure in the model of Magistrale et al. (1996).

The variation among the models of the basin-fill structure is significant. Wald and Graves (1998) compared data from the 1992 Landers earthquake with synthetic waveforms at periods $>2 \mathrm{sec}$ produced by three 3D models of the Los Angeles, San Fernando, and San Gabriel basins. They looked at the early version of the 3D tomographic model used by
Haase et al. (1996), at the geology-based model of Magistrale et al. (1996) (which included the earlier version of their San Fernando basin model), and at the model of Graves (1996) based on seismic modeling studies. For the San Fernando basin, there are significant differences in the models of the basin-fill seismic velocities and the effective depth of the San Fernando basin. Of the three models, synthetics based on Graves' model fit wave shape, duration, and amplitude in the San Fernando basin markedly better than the other two. In the San Fernando basin, Graves' model has only a few layers, with a reasonably strong gradient at $0.5-1 \mathrm{~km}$ depth going from 1 to $1.5-2 \mathrm{~km} / \mathrm{sec}$, and a strong contrast at the bottom of the basin, which dips below $5 \mathrm{~km}$ depth.

Our modeling requires a strong gradient in the upper basin and a moderately deep ( $4 \mathrm{~km})$ depth of the entire basin. The most recent Magistrale model for the San Fernando Valley and Graves' model have strong gradients in the upper basin. Our depth for the entire basin falls between the two models. However, our depth of basin is constrained primarily relative to the depth of source because it is the tendency of this interface to turn energy up toward the upper basin edge that is reflected in the data.

Hough et al. (1995) find large variations in Northridge aftershock waveforms from earthquakes just a few kilometers from each other. One event, about $6 \mathrm{~km}$ deep, has large basin-edge-generated surface waves. Two others within a few kilometers of the first one, one at $2 \mathrm{~km}$ and the other at $10 \mathrm{~km}$, have almost no basin-generated phases. This indicates a strong sensitivity of the waveforms to the sourcereceiver geometry. They suggest this sensitivity is due to complex basin-edge structures and that either near-vertical arrivals deficient in $S V$ energy may be particularly sensitive to this structure and fail to generate Rayleigh waves effectively or variations in the dip of the basin/basement interface will control where surface waves are generated. Figure 13 shows the sensitivity of the response of our model to source location. Shifting the source even halfway under the basin edge removes most basin effects on the tangential component. This demonstrates that simple 2D models are sensitive to source location, and, even for $S H$ waves, the variation can be dramatic. Also, in our study on the aftershock of the 1987 Whittier Narrows earthquake, we point out the sensitivity of basin-edge phases to the vertical radiation pattern of the

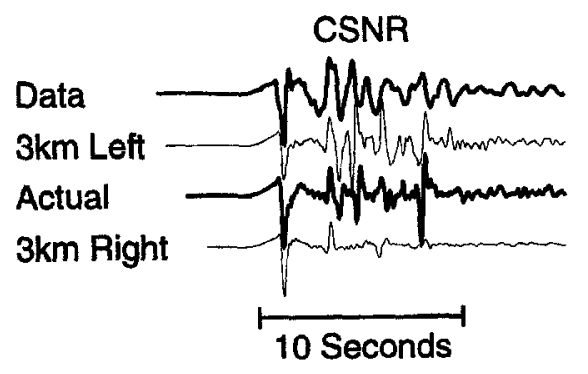

Figure 13. Effect on the waveform at CSNR from horizontal shifts in the source location. 
source (Scrivner and Helmberger, 1994). Energy in the direct arrival and the basin-generated phases are leaving the source at different take-off angles, particularly when the source is just below the basin. Therefore, the vertical radiation pattern of the source can have a significant impact. Of course, the sensitivity of the waveforms to source characteristics is potentially quite useful. Changes in source location and mechanism can illuminate different portions of the basin cross section.

For the foregoing reasons, shallow events produce the most problematic recordings with respect to correcting for propagation. In fact, even estimating the depths of shallow earthquakes is difficult, as discussed in Luccio et al. (1999). Thus, we suggest that some of the recent analyses for nonlinearity in Northridge strong motions test their results against deep events and shallow events separately. Because deep events have less of a chance of producing edge effects than shallow events, we would expect these results to be the most meaningful. However, to separate propagational behavior from nonlinearity requires $3 \mathrm{D}$ models because aftershocks and main events seldom sample identical paths. To achieve this level of accuracy at $5 \mathrm{~Hz}$ remains a very difficult problem.

\section{Conclusions}

A strong contrast is seen in the data from the two Northridge aftershocks studied here. The deep event is mostly insensitive to the basin; the strongest path effects are nearreceiver ringing and amplifications. Waveforms from the shallow event record large basin-generated surface waves with periods that are explained by strong gradients in the upper basin. The waveforms also indicate interactions of the wavefield with structure below the basin. They also show site response effects similar to those for the deep event. Array analysis of the largest basin surface waves indicate they are on azimuth from the source and can be modeled with a 2D structure.

The data is fit well by a model with a slow upper basin down to $1.5 \mathrm{~km}$, a deeper basin down to $3.5 \mathrm{~km}$, and a gradient in the background model at $5.5 \mathrm{~km}$ depth. The velocity contrast between the upper and lower basins needs to be large to generate multiple cycles in the surface waves. The velocity contrast and depth of the upper basin are sensitive parameters of the upper basin, whereas the waveforms are less sensitive to the steepness of the basin edge. The location of the bottom of the deep basin, relative to the source, is an important parameter. The closer this interface is to the source, the more energy from the source is turned up into the basin. The gradient beneath the basin, at $5.5 \mathrm{~km}$ depth, reflects energy around the basin and introduces a $\pi / 2$ phase advance to the direct arrival. In addition, a gradient is needed under the Santa Monica Mountains to turn the energy sharply around the basin.

A comparison has been made with other models that have been used in $2 \mathrm{D}$ and $3 \mathrm{D}$ waveform simulations. The gradient at $5.5 \mathrm{~km}$ depth is also in the background model of Magistrale et al. (1996) and is essentially the model of Hadley and Kanamori (1977) for the central Transverse Ranges. Our basin model is bracketed by the most recent San Fernando basin model of Magistrale, and the model from Graves (1996). Both have strong gradients in the upper basin, but the depth of overall basin is shallower and deeper than ours, respectively. Two-dimensional modeling may be useful for refining 3D models of sedimentary basin, allowing us to determine points of particular sensitivity in models for a given data set.

As efforts are made to improve existing 3D models of the southern California crust, a variety of data sets will be used to constrain the structure of basins. In some portions of the basins, at shallow to moderate depths, borehole logs will place precise constraints on material properties and possibly depth-to-basement rock. To complete the coverage of the basins, interpolations will be made based on geologic cross sections, tomographic models, active seismic lines, and other data. Modeling broadband seismic waveforms has the potential to indicate where impedance contrasts are needed in models and the strength of contrast needed. As the number of earthquakes recorded by modern digital instruments increases, the azimuthal coverage of basins by waveform data will improve. Waveform data should be given a significant role in the development of future 3D models. After all, the primary application of 3D velocity models of sedimentary basins is to simulate ground motions at these periods.

\section{Acknowledgments}

The authors thank Sue Hough and Harold Magistrale for their thoughtful reviews that significantly improved this article. The authors acknowledge the Southern California Earthquake Center (SCEC) for access to the portable instrument data from the Northridge aftershock sequence. This research was supported by SCEC under Contract Number 89-20136 and by the USGS (00HQGR0035). The views and conclusions contained in this document are those of the authors and should not be interpreted as necessarily the official policies of the U.S. Government. Division of Geological and Planetary Sciences Contribution Number 8665.

\section{References}

Beresnev, I. A., and G. M. Atkinson (1998). Stochastic finite-fault modeling of ground motions from the 1994 Northridge, California, earthquake, I. Validation on rock sites, Bull. Seism. Soc. Am. 88, 1392-1401.

Beresnev, I. A., G. M. Atkinson, P. A. Johnson, and E. H. Field (1998a), Stochastic finite-fault modeling of ground motions from the 1994 Northridge, California, earthquake. II. Widespread nonlinear response at soil sites, Bull. Seism. Soc. Am. 88, 1402-1410.

Beresnev, I. A., E. H. Field, K. V. D. Abeele, and P. A. Johnson (1998b). Magnitude of nonlinear sediment response in Los Angeles basin during the 1994 Northridge, California, earthquake, Bull. Seism. Soc. Am. 88, 1079-1084.

Clayton, R. W., and B. Engquist (1980). Absorbing boundary conditions for wave-equation migration, Geophysics 45, 895-904.

Cultrera, G., D. M. Boore, W. B. Joyner, and C. M. Dietel (1998). Nonlinear soil response in the vicinity of the Van Norman Complex following the 1994 Northridge, California, earthquake, Bull. Seism. Soc. Am., submitted. 
Dreger, D. S. (1994). Empirical Green's function study of the January 17, 1994 Northridge, California earthquake, Geophys. Res. Lett. 21, 2633-2636.

Duke, C. M., J. A. Johnson, Y. Kharraz, K. W. Campbell, and N. A. Malpiede (1971). Subsurface site conditions and geology in the San Fernando earthquake area, UCLA-ENG 7206, School of Engineering, University of California, Los Angeles.

Edelman, A., and F. Vernon (1994). The Northridge portable instrument aftershock data set, Technical Report, IDA, http://yin.ucsd.edu/ANZA/ portable/nr_rep.html.

Field, E. H., P. A. Johnson, I. A. Beresnev, and Y. H. Zeng (1997). Nonlinear ground-motion amplification by sediments during the 1994 Northridge earthquake, Nature 390, 599-602.

Field, E. H., Y. H. Zeng, P. A. Johnson, and I. A. Beresnev (1998). Nonlinear sediment response during the 1994 Northridge earthquake: observations and finite source simulations, J. Geophys. Res. 103, 2686926883.

Frankel, A., S. Hough, P. Friberg, and R. Busby (1991). Observations of Loma Prieta aftershocks from a dense array in Sunnyvale, California, Bull. Seism. Soc. Am. 81, 1900-1922.

Graves, R. W. (1996). Simulating seismic-wave propagation in 3D elastic media using staggered-grid finite-difference, Bull. Seism. Soc. Am. 86, 1091-1106.

Haase, J. S., E. Hauksson, F. Vernon, and A. Edelman (1996). Modeling of ground motion from a 1994 Northridge aftershock using a tomographic velocity model of the Los Angeles basin, Bull. Seism. Soc. Am. 86, S156-S167.

Hadley, D., and H. Kanamori (1977). Seismic structure of the Transverse Ranges, California, Geol. Soc. Am. Bull. 88, 1469-1478.

Hartzell, S., A. Leeds, A. Frankel, and J. Michael (1996). Site response for urban Los Angeles using aftershocks of the Northridge earthquake, Bull. Seism. Soc. Am. 86, S168-S192.

Hauksson, E., and J. S. Haase (1997). Three-dimensional $V_{p}$ and $V_{s}$ velocity models of the Los Angeles basin and central Transverse Ranges, California, J. Geophys. Res. 102, 5423-5453.

Hauksson, E., L. M. Jones, and K. Hutton (1995). The 1994 Northridge earthquake sequence in California: seismological and tectonic aspects, J. Geophys. Res. 100, 12335-12355.

Helmberger, D. V., and J. E. Vidale (1988). Modeling strong motions produced by earthquakes with two-dimensional numerical codes, Bull. Seism. Soc. Am. 78, 109-121.

Hough, S. E., C. Dietel, G. Glassmoyer, and E. Sembera (1995). On the variability of aftershock ground motions in the San Fernando Valley, Geophys. Res. Lett. 22, 727-730.

Kanamori, H., and D. Hadley (1975). Crustal structure and temporal velocity change in southern California, Pageoph 113, 257-280.

Luccio, F. D., L. M. Jones, L. Zhu, E. Hauksson, and D. Helmberger (1998).
Resolution of focal depth determinations in southern California, Bull. Seism. Soc. Am., submitted.

Magistrale, H., K. McLaughlin, and S. Day (1996). A geology-based 3D velocity model of the Los Angeles Basin sediments, Bull. Seism. Soc. Am. 86, 1161-1166.

Olsen, K. B., and R. J. Archuleta (1996). 3-Dimensional simulation of earthquakes on the Los Angeles fault system, Bull. Seism. Soc. Am. $86,575-596$.

Olsen, K. B., R. J. Archuleta, and J. R. Matarese (1995). Three-dimensional simulation of a magnitude 7.75 earthquake on the San Andreas fault, Science 270, 1628-1632.

Pitarka, A., and K. Irikura (1996). Basin structure effects on long-period strong motions in the San Fernando Valley and the Los Angeles basin from the 1994 Northridge earthquake and an aftershock, Bull. Seism. Soc. Am. 86, S126-S137.

Scrivner, C. W., and D. V. Helmberger (1994). Seismic waveform modeling in the Los Angeles basin, Bull Seism. Soc. Am. 84, 1310-1326.

Song, X. J., and D. V. Helmberger (1997). Northridge aftershocks, a source study with TERRAscope data, Bull. Seism. Soc. Am. 87, 1024-1034.

Su, F., J. G. Anderson, and Y. H. Zeng (1998). Study of weak and strong ground motion including nonlinearity from the Northridge, California, earthquake sequence, Bull. Seism. Soc. Am. 88, 1411-1425.

Thio, H. K., and H. Kanamori (1996). Source complexity of the 1994 Northridge earthquake and its relation to aftershock mechanisms, Bull. Seism. Soc. Am. 86, S84-S92.

Tinsley, J. C., and T. E. Fumal (1985). Mapping quaternary sedimentary deposits for areal variations in shaking response, in Evaluating Earthquake Hazards in the Los Angeles Region-An Earth-Science Perspective, U.S. Geol. Surv. Profess. Pap. 1360, 101-125.

Vidale, J. E., and D. V. Helmberger (1988). Elastic finite-difference modeling of the 1971 San Fernando, California, earthquake, Bull. Seism. Soc. Am. 78, 122-141.

Vidale, J., D. V. Helmberger, and R. W. Clayton (1985). Finite-difference seismograms for SH waves, Bull. Seism. Soc. Am. 75, 1765-1782.

Wald, D., and R. Graves (1998). The seismic response of the Los Angeles basin, California, Bull. Seism. Soc. Am. 88, 337-356.

Wald, D. J., T. H. Heaton, and K. W. Hudnut (1996). The slip history of the 1994 Northridge, California, earthquake determined from strongmotion, teleseismic, GPS, and leveling data, Bull. Seism. Soc. Am. 86, S49-S70.

Zhao, D., and H. Kanamori (1995). The 1994 Northridge earthquake: 3-D crustal structure in the rupture zone and its relation to the aftershock locations and mechanisms, Geophys. Res. Lett. 22, 763-766.

Seismological Laboratory

California Institute of Technology

Pasadena, California 91109

Manuscript received 4 November 1997. 